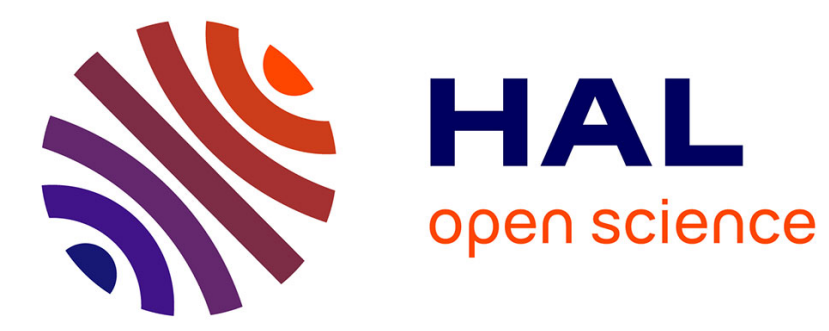

\title{
Methods to investigate the role of Rho GTPases in osteoclast function
}

Anne Morel, Anne Blangy, Virginie Vives

\section{To cite this version:}

Anne Morel, Anne Blangy, Virginie Vives. Methods to investigate the role of Rho GTPases in osteoclast function. Methods in Molecular Biology, 2018, Rho GTPases. Methods and Protocols, 1821, pp.219-233. 10.1007/978-1-4939-8612-5_15. hal-01887147

\section{HAL Id: hal-01887147 https://hal.science/hal-01887147}

Submitted on 3 Oct 2018

HAL is a multi-disciplinary open access archive for the deposit and dissemination of scientific research documents, whether they are published or not. The documents may come from teaching and research institutions in France or abroad, or from public or private research centers.
L'archive ouverte pluridisciplinaire HAL, est destinée au dépôt et à la diffusion de documents scientifiques de niveau recherche, publiés ou non, émanant des établissements d'enseignement et de recherche français ou étrangers, des laboratoires publics ou privés. 
"Methods to investigate the role of Rho GTPases in osteoclast function"

${\text { Anne } \text { Morel }^{1,2} \text {, Anne Blangy }}^{1,2, @}$ and Virginie Vives ${ }^{1,2}$

${ }^{1}$ CRBM CNRS UMR 5237, Montpellier, France

${ }^{2}$ Montpellier University, Montpellier, France

${ }^{\circledR}$ Corresponding author:

Anne Blangy

Email: anne.blangy@crbm.cnrs.fr

Address:

CRBM CNRS UMR 5237

RhoGTPases in osteoclast biology

1919 route de Mende

34293 Montpellier Cedex 5

FRANCE

Tel: +33434359508

Fax: +33434359410 


\section{i. Summary/Abstract.}

The actin cytoskeleton is essential for the biology of osteoclasts, in particular during bone resorption. As key regulators of actin dynamics, the small GTPases of the Rho family are very important in the control of osteoclast activity. The study of Rho GTPase signaling pathways is essential to uncover the mechanisms of bone resorption and can have interesting applications for the treatment of osteolytic diseases. In this chapter, we describe various technics to obtain primary osteoclasts from murine bone marrow cells, to measure RhoGTPase activation levels, to monitor bone resorption activity of osteoclasts and to introduce the expression of proteins of interest using a retroviral approach. We illustrate the different methods with experimental examples of the effect of Rac1 activation by the exchange factor Dock5 on bone resorption by osteoclasts. 


\section{ii. Key Words}

Osteoclast, osteoporosis, GTPase, Rho, Rac, Cdc42, Dock5, actin, GEF, GAP 


\section{Introduction.}

Osteoclasts are multinucleated myeloid cells specialized for bone resorption. In tight coordination with osteoblasts, the cells responsible for bone formation, they ensure the maintenance of bone homeostasis throughout life. Still, various situations can break this balance between bone resorption and bone formation in favor of bone resorption by osteoclasts, which leads to progressive bone loss and osteoporosis. It can be a consequence for instance of hormonal disorders such as menopause [1], of cancer, for instance multiple myeloma and bone metastases [2], and of inflammatory diseases including rheumatoid arthritis [3]. Controlling osteoclast activity to prevent pathological bone loss is an important challenge in osteolytic diseases; the identification of novel targets to develop anti-osteolytic treatments results an essential goal. Primary osteoclasts can be differentiated ex vivo, from mouse bone marrow or peripheral human blood for instance, using the cytokines macrophagecolony stimulating factor (M-CSF) and receptor activator of nuclear factor kappa B ligand (RANKL) [4]. These osteoclasts are functional to resorb the bone and they can be manipulated genetically or treated with chemical compounds to monitor the effect on their bone resorption activity.

To resorb the bone, osteoclasts assemble a specific adhesion structure called the sealing zone or actin ring, which seals the cell onto the surface of the bone. Within the actin ring, the osteoclasts secrete protons and proteases to dissolve and degrade ${ }_{2}$ respectively $y_{2}$ the mineral and the protein phases of the bone matrix. The sealing zone is based on a ring of densely packed podosomes, which are actin-based adhesion structures [5]. Thus, the regulation of actin dynamics by Rho GTPase signaling pathways plays an essential role during bone resorption [6]. In fact, actin polymerization and depolymerization mediates the adhesion of osteoclasts, their migration and the assembly/disassembly cycles of the sealing zone. The regulation of actin dynamics is also crucial during the differentiation of osteoclasts, which 
involves in particular cell-cell fusions [7]. Not surprisingly, various Rho GTPases are expressed in osteoclasts [8] and they play important functions in many aspects of osteoclast biology, from differentiation and fusion of osteoclast precursors to osteoclast migration and bone resorption activity [9], including RhoA [10, 11], Rac1 and Rac2 [12-15], RhoU/Wrch1[8, 16, 17], RhoE/Rnd3 [18] and Cdc42 [19].

Rho GTPases alternate between active GTP-bound and inactive GDP-bound states. As other small GTPases from the Ras superfamily, the activity cycle of Rho GTPases is regulated on one hand by guanine nucleotide exchange factors (GEFs), which activate the GTPases by catalyzing the release of GDP and allowing the binding of GTP $[20,21]$, and on the other hand GTPase-activating proteins (GAPs), which inactivate the GTPases by stimulating their GTP hydrolysis activity [22]. Once activated, Rho GTPases can bind numerous effector proteins to mediate their effect on actin dynamics. Various Rho GTPase GEFs [8] and GAPs are expressed in osteoclasts. Some were shown to control different processes in osteoclasts, namely GEFs for Rac: Dock5 [23], Vav3 [24] and FARP2 [25], for Cdc42: FGD6 [26] and for RhoA: Arhgef3 [27]; and GAPs for RhoA: Myo9b [28] and for Cdc42: Cdc42GAP [19]. Targeting RhoGTPase activity in osteoclasts with pharmaceutical compounds that affect these regulators constitutes a promising therapeutic approach to modulate the pathological excess of osteoclast activity [29].

The aim of this chapter is to describe a method to differentiate functional osteoclasts from monocytes obtained from mouse bone marrow. We then describe a method to assess the activation of the major Rho GTPases RhoA, Rac and Cdc42 in osteoclasts. We also present a technique to monitor the bone resorption activity of osteoclasts in culture. Finally we propose a retrovirus-mediated protocol to express proteins of interest in osteoclasts. We illustrate these protocols with examples of the effect of exchange factor Dock5 on the activation of Rac in osteoclasts and the consequences on their bone resorption activity. 


\section{Materials}

\subsection{Mouse dissection and bone marrow macrophages (BMMs) isolation}

1. Phosphate buffered-saline (PBS, Lonza).

2. Fetal Bovine Serum (FBS), heat inactivated at $56^{\circ} \mathrm{C}$ for 30 minutes (BioWest).

3. $2 \%$ FBS diluted in PBS.

4. 15-mL conical tubes.

5. 6-well tissue culture plates, $10-\mathrm{mL}$ syringes, gloves, sterile needles (23- and 26gauge) and sterile gauze.

6. Bunsen burner.

7. $70 \%$ ethanol.

8. Dissection tools: 2 pairs of chirurgical scissors $(14 \mathrm{~cm}$, straight, sharp and $11.5 \mathrm{~cm}$, straight, sharp), scalpel blades and forceps (14 cm, straight, serrated tips).

9. Sterile $70-\mu \mathrm{m}$ cell strainers for $50 \mathrm{~mL}$ conical tubes (Sigma-Aldrich).

10. $\alpha$-minimal essential medium $(\alpha$-MEM) growth medium: (Lonza) containing $10 \%$ heat inactivated FBS, $2 \mathrm{mM}$ glutamine (Lonza) and $100 \mathrm{U} / \mathrm{mL}$ penicillin and streptomycin (Lonza).

11. Malassez cell counting chamber.

12. $150-\mathrm{mm}$ tissue culture dishes.

13. 100-mm sterile Petri dishes.

14. M-CSF (10 $\mu \mathrm{g}$, Myltenyi). Dissolve $10 \mu \mathrm{g}$ in $1 \mathrm{~mL}$ of sterile PBS containing 1 $\mathrm{mg} / \mathrm{mL}$ ultra pure bovine serum albumin (BSA) (Sigma-Aldrich) to yield a stock concentration of $100 \mathrm{ng} / \mathrm{mL}$. Store in $200 \mu \mathrm{L}$ aliquots at $-80^{\circ} \mathrm{C}$.

15. Tissue culture room with regular equipment including a class II laminar air-flow hood, a humidity and $\mathrm{CO}_{2}$ regulated-incubator, a low-speed Sorval Legend XI 
centrifuge or equivalent, to spin down cells, and an inverted bright field microscope: Leica DM IL equipped with 10x, 20x and 40x HI PLAN objectives or equivalent, for live-cell observation.

\section{Tissue culture facility: laminar flow cabinet, incubator, microscope, centrifuge.}

\subsection{In vitro osteoclast differentiation}

1. PBS.

2. $0.25 \%$ Trypsin - 1 mM EDTA in PBS (Lonza).

3. $\alpha$-MEM growth medium.

4. Malassez cell counting chamber.

5. 24-well tissue culture plates.

6. M-CSF.

7. RANKL (10 $\mu \mathrm{g}$, Myltenyi). Dissolve $10 \mu \mathrm{g}$ in $1 \mathrm{~mL}$ of sterile PBS containing 1 $\mathrm{mg} / \mathrm{mL}$ ultra pure BSA (Sigma-Aldrich) to yield a stock concentration of 100 $\mathrm{ng} / \mathrm{mL}$. Store in $200 \mu \mathrm{L}$ aliquots at $-80^{\circ} \mathrm{C}$.

\subsection{Resorption assay}

1. 24-well tissue culture plates.

2. $\alpha$-MEM growth medium, M-CSF and RANKL

3. 15-mL conical tubes.

4. Accutase (Sigma-Aldrich).

5. Osteo Assay 96 stripwell plates, which are coated with inorganic crystalline calcium phosphate that mimics bone (Corning).

6. 96-well tissue culture plates.

7. PBS.

8. Formalin 3.6\%: formalin 36\% diluted 10 times in PBS. 
9. Ethanol.

10. Acetone.

11. Sodium acetate/sodium tartrate solution: sodium acetate $0.1 \mathrm{M}$, sodium tartrate $50 \mathrm{mM}, \mathrm{pH} 5$.

12. Fast red violet LB salt: $30 \mathrm{mg}$ Fast Red Violet LB salt (Sigma-Aldrich) in $10 \mathrm{~mL}$ of distilled water. Store $1 \mathrm{~mL}$ aliquots at $-20^{\circ} \mathrm{C}$.

13. NN dimethylformamide (DMF)-naphtol: $50 \mathrm{mg}$ Naphtol AS - MX phosphate (Sigma-Aldrich) in $5 \mathrm{~mL}$ of DMF. Store $500 \mu \mathrm{L}$ aliquots $-20^{\circ} \mathrm{C}$.

14. TRAP staining solution, to be prepared upon use: $50 \mathrm{~mL}$ of sodium acetate / sodium tartrate solution $+1 \mathrm{~mL}$ of fast red violet salt $+500 \mu \mathrm{L}$ of $\mathrm{NN}$ dimethylformamide (DMF)-naphtol.

15. $1 \%$ Bleach in distilled water.

16. $5 \%$ Silver nitrate $\left(\mathrm{AgNO}_{3}\right)$ in distilled water.

17. $10 \%$ Formalin (Sigma-Aldrich) in distilled water.

18. $5 \%$ Carbonate sodium $\left(\mathrm{Na}_{2} \mathrm{CO}_{3}\right)$ in $10 \%$ formalin.

19. ImageJ software, an open source image processing program (free download at https://imagej.net), with cell-counter plugin (https://imagej.nih.gov/ij/plugins/cellcounter.html).

20. Transmission Nikon SMZ1000 stereomicroscope equipped with a Achro 0,5x objective and a Nikon DXM 1200F CCD camera, or equivalent.

\subsection{Rho-GTPases activation assay}

1. 6-well tissue culture plates.

2. $\alpha$-MEM growth medium, M-CSF and RANKL.

3. Dock5 inhibitor C21 CAS 54129-15-6 (Fisher Scientific), prepare a $20 \mathrm{mM}$ stock in DMSO and store in aliquots at $4^{\circ} \mathrm{C}$. 
4. PBS.

5. FISH buffer: $10 \%$ glycerol, $50 \mathrm{mM}$ Tris- $\mathrm{HCl} \mathrm{pH}$ 7.4, $100 \mathrm{mM} \mathrm{NaCl}, 1 \%$ IGEPAL (Sigma-Aldrich) and $2 \mathrm{mM} \mathrm{MgCl}_{2}$.

6. $1000 \times$ protease inhibitor cocktail (Sigma-Aldrich).

7. 1.5-mL microcentrifuge tubes.

8. Cell lifters.

9. $4 \times$ Laemmli buffer: $0.25 \mathrm{M}$ Tris- $\mathrm{HCl} \mathrm{pH} 6.8,8 \%$ sodium dodecylsulfate (SDS), $40 \%$ glycerol, $8 \% \beta$-mercaptoethanol and $0.02 \%$ bromophenol blue.

10. PAK-GST gluthatione sepharose beads (Cytoskeleton): reconstituted in $500 \mu \mathrm{L}$ of sterile distilled water to yield a stock concentration of $1 \mathrm{mg} / \mathrm{mL}$. Store $20 \mu \mathrm{L}$ aliquots at $-80^{\circ} \mathrm{C}$.

11. $2 \times$ Laemmli buffer is obtained by dilution of $4 \times$ Laemmli in water.

12. Anti-Rac1 antibody (Millipore).

13. ImageJ software.

\subsection{Rho-GTPases overexpression}

1. 100-mm tissue culture plates.

2. Dulbecco's Modified Eagle Medium (DMEM) growth medium (Lonza) containing $10 \%$ fetal bovine serum, $2 \mathrm{mM}$ glutamine (Lonza) and $100 \mathrm{U} / \mathrm{mL}$ penicillin and streptomycin (Lonza).

3. $1.5-\mathrm{mL}$ microcentrifuge tubes.

4. $150 \mathrm{mM}$ sodium chloride $(\mathrm{NaCl})$ dissolved in sterile water.

5. Jet PEI DNA transfection reagent (Polyplus).

6. pMXS-Puro retroviral expression vector (Cell Biolabs). 
7. Friend MLV-based Gag-Pol expression vector pC57GP [30], generous gift from Marc Sitbon, Institute of Molecular Genetics of Montpellier (IGMM), Montpellier, France.

8. VSV-G envelope glycoprotein expression vector pCSI-G [31], generous gift from Marc Sitbon, Institute of Molecular Genetics of Montpellier (IGMM), Montpellier, France.

9. Salmon sperm DNA (Sigma-Aldrich).

10. $0.45-\mu \mathrm{m}$ disposable syringe filter units.

11. 20-mL syringes.

12. Sterile 100-mm Petri dishes.

13. $\alpha$-MEM growth medium.

14. M-CSF.

15. Hexadimethrine bromide (Sigma-Aldrich), $8 \mu \mathrm{g} / \mu \mathrm{L}$ dissolved in sterile water. Store in aliquots at $4^{\circ} \mathrm{C}$.

16. Puromycine dihydrochloride (Sigma-Aldrich), $10 \mu \mathrm{g} / \mu \mathrm{L}$ dissolved in sterile water. Store in aliquots at $-20^{\circ} \mathrm{C}$.

\section{Methods}

\subsection{Mouse dissection and bone marrow macrophages (BMMs) isolation}

1. Pipet $5 \mathrm{~mL}$ of $2 \%$ FBS in PBS in each well of a 6 -well tissue culture plate and place $20 \mathrm{~mL}$ of the same solution in a $50 \mathrm{~mL}$ conical tube. Keep both on ice during all the procedure.

2. Euthanize animals according to appropriate ethical guidelines. The commonly used method for euthanasia is cervical dislocation. 
3. All procedures involving mouse dissection should be done aseptically next to a Bunsen burner and wearing gloves. Generously spread euthanized mice with $70 \%$ ethanol to minimize the chance of cell culture contamination.

4. With 14-cm scissors, make a small 5-mm cut on the ventral surface of the skin. Lift the skin to make sure the underlying peritoneum is not cut.

5. Grab the skin on either side of the cut and pull firmly in opposite directions along the longitudinal axis, until the skin is pulled off the legs. Completely separate the skin from the hind legs by pulling; be careful not to break the bones. Thereby the muscles of the hind legs are exposed.

6. Separate the legs from the body at the femur-ilium joint with $11.5-\mathrm{cm}$ scissors, the femur head should remain with the leg. Place each leg in cold 2\% FBS in PBS in a side well of the 6-well plate.

7. Cut off the foot and carefully remove most of the bones muscles using $11.5-\mathrm{cm}$ scissors. Place each leg in cold 2\% FBS in PBS in a middle well of the 6-well plate.

8. Complete flesh removal with gauze to ensure that the bones are clean and free from any soft tissue. Separate the femur and tibia at the joint using $11.5-\mathrm{cm}$ scissors. Spray the 4 bones with 70\% ethanol and distribute them in ice cold PBS 2\% FBS in the 2 clean wells that are left in the 6-well plate.

9. Fill up a $10-\mathrm{mL}$ syringe with $2 \%$ FBS in PBS from the $50-\mathrm{mL}$ conical tube and attach a 23-gauge needle.

10. Cut the femurs in the middle using a scalpel blade to expose bone marrow. For each half, hold securely with forceps at mid-shaft, insert the needle into the cut-end side and flush the bone marrow into the $50-\mathrm{mL}$ conical tube. Repeat until all the bone marrow is completely flushed out, the bone should whiten. 
11. Attach a 26-gauge needle to the same syringe and repeat steps 9 and 10 to flush out the bone marrow of the tibias.

12. From this step, all procedures should be performed in a class II laminar air-flow hood.

13. Pipet up and down the bone marrow suspension several times in the $50-\mathrm{mL}$ conical tube to break up the aggregates.

14. Filter the suspension through a $70-\mu \mathrm{m}$ cell strainer adapted onto a new $50-\mathrm{mL}$ conical tube, in order to eliminate bone particles and residual aggregates.

15. Pellet bone marrow cells by spinning at $5,000 \mathrm{xg}$ for 5 minutes at room temperature.

16. Aspirate the supernatant, being careful not to disturb the cell pellet and resuspend the pellet in $10 \mathrm{~mL}$ of $\alpha$-MEM growth medium.

17. Count cells with a Malassez counting cell chamber. Bone marrow extraction from one mouse produces 1 to $1.5 \times 10^{8}$ cells. Plate $3 \times 10^{7}$ cells per 150 -mm tissue culture dish. Adjust medium to $15 \mathrm{~mL}$ per $150 \mathrm{~mm}$ tissue culture dish and mix well. Grow cells overnight in a humidified incubator at $37^{\circ} \mathrm{C}$ with $5.5 \% \mathrm{CO}_{2}$. Stromal cells will attach whereas osteoclast precursors will remain in suspension.

18. Collect the supernatant into a 50-mL conical tube and pellet the cells at $5,000 \mathrm{xg}$ for $5 \min ($ see Note 1$)$.

19. Resuspend the pellet containing osteoclast precursors with $10 \mathrm{~mL}$ of $\alpha$-MEM growth medium and count cells with a Malassez counting cell chamber. One should be able to collect around $50 \%$ of the cells counted at step 17 . Plate $5 \times 10^{6}$ cells per 100-mm Petri dish (see Note 2) in $10 \mathrm{~mL}$ of $\alpha$-MEM growth medium supplemented with 100 ng/mL M-CSF. Culture for 5 days to obtain BMMs (see Fig. 1A), change medium and cytokine every other day (see Note 3). 


\subsection{In vitro osteoclast differentiation}

1. Rinse 100-mm Petri dishes containing BMMs with PBS and remove supernatant.

2. Lift BMMs with $1 \mathrm{~mL}$ of trypsin-EDTA per dish, suspend in $10 \mathrm{~mL}$ of $\alpha$-MEM growth medium and spin down 5 minutes at $5,000 \mathrm{xg}$.

3. Resuspend pellet with $10 \mathrm{~mL}$ of $\alpha$-MEM growth medium and count cells using the Malassez counting cell chamber. On average, expect 2 to $5 \times 10^{5}$ BMMs per Petri dish.

4. Plate $3 \times 10^{4} \mathrm{BMMs}$ per well in a 24 -well tissue culture plate in $2 \mathrm{~mL}$ of $\alpha$-MEM growth medium supplemented with $30 \mathrm{ng} / \mathrm{mL}$ M-CSF and $50 \mathrm{ng} / \mathrm{mL}$ RANKL.

5. Change medium every 2 days. Cells will start to fuse and form multinucleate cells 2 days later (see Fig. 1B). Osteoclasts will be obtained after another 1 to 2 days (see Fig. 1C).

\subsection{Resorption assay}

1. Place $3 \times 10^{4}$ BMMs (from subheading 3.2, step 3) per well in a 24 -well tissue culture plate in $2 \mathrm{~mL}$ of $\alpha$-MEM growth medium with $30 \mathrm{ng} / \mathrm{mL} \mathrm{M}-\mathrm{CSF}$ and 50 ng/mL RANKL. Prepare 10 wells per condition to be tested.

2. After 2 days, lift the differentiating osteoclasts (pre-osteoclasts) with $100 \mu \mathrm{L}$ of Accutase per well. Pool the cells from the 10 wells in a $15-\mathrm{mL}$ conical tube and add 1-mL of $\alpha$-MEM growth medium supplemented with $30 \mathrm{ng} / \mathrm{mL}$ M-CSF and 50 $\mathrm{ng} / \mathrm{mL}$ RANKL. The volume should be $2.5 \mathrm{~mL}$; if it is less, adjust with medium.

3. Dispense $225 \mu \mathrm{L}$ of the suspension per well in 8 wells of an Osteo Assay stripwell and in 1 well of a 96-well tissue culture plate. The latter serves as a positive control to monitor osteoclast differentiation. 
4. Change medium every other day.

5. Once osteoclasts appear in the control well, continue osteoclast culture in the Osteo Assay stripwell for 2 more days (see Note 4).

6. To count osteoclasts, stain 4 wells of the Osteo Assay stripwell for Tartrate Resistant Acid Phosphatase (TRAP) activity. TRAP enzyme is characteristic of osteoclasts, it converts p-nitrophenyl phosphate to p-nitrophenol under acidic conditions. For TRAP staining, fix cells for 10 minutes with $100 \mu \mathrm{L}$ per well of $3.6 \%$ formalin, wash once with PBS, permeabilize with ethanol:acetone (1:1) for 1 minute, aspirate and add $200 \mu \mathrm{L}$ of freshly thawed TRAP staining solution. In osteoclasts, the TRAP enzyme will convert the Naphtol AS - MX phosphate, the reaction product will combined with Fast Red Violet LB Salt Dye and result in a pink-red precipitate in the cell. Incubate for 20 minutes to $1 \mathrm{~h}$ at $37^{\circ} \mathrm{C}$ until the pink-red stain develops. Eliminate TRAP staining solution and air dry..

\section{Image the entire wells with a Nikon SMZ1000 stereomicroscope or equivalent.}

8. Quantify manually the total number of osteoclasts in each well with ImageJ software using the cell-counter plugin.

9. Stain the remaining 4 wells of the Osteo Assay stripwell with von Kossa, to reveal the mineralized substrate in black and measure the area resorbed by osteoclasts that will appear as white hole.., Aspirate the culture medium, add $100 \mu \mathrm{L}$ of $1 \%$ bleach for 5 minutes and wash twice with distilled water. Drain upside down on a paper towel and add $100 \mu \mathrm{L}$ of $5 \% \mathrm{AgNO}_{3}$ for 10 minutes. Wash with distilled water for 5 minutes, drain and add $100 \mu \mathrm{L}$ of $5 \% \mathrm{Na}_{2} \mathrm{CO}_{3}$ for 4 minutes. The mineral surface becomes black and the resorption areas will appear white. Drain solution and air-dry prior to imaging. 
10. Imaging the entire wells with a Nikon SMZ1000 stereomicroscope or equivalent.

11. Quantify the total resorption area in each well with ImageJ software.

12. To obtain osteoclast specific activity, divide the average resorption area in the 4 wells stained with von Kossa by the average number of osteoclasts in the 4 wells stained with TRAP (see Fig. 2).

\subsection{Rac1 activation assay.}

1. Plate $15 \times 10^{4}$ BMMs (from step 3 of subheading 3.2 ) in each well of a 6 -well tissue culture plate in $5 \mathrm{~mL}$ of $\alpha$-MEM growth medium supplemented with $30 \mathrm{ng} / \mathrm{mL} \mathrm{M}$ CSF and $50 \mathrm{ng} / \mathrm{mL}$ RANKL. Prepare a minimum of 3 wells per condition. Change medium every 2 days until osteoclasts appear.

2. Treat osteoclasts in at least three wells with $100 \mu \mathrm{M}$ of $\mathrm{C} 21$ diluted in culture medium for 1 hour and treat the same number of control wells with $0.5 \%$ DMSO (see Note 5).

3. From this step, proceed on ice in a cold room.

4. Wash osteoclasts with ice cold PBS and lyse cells for 5 minutes with $75 \mu \mathrm{L}$ per well of FISH buffer supplemented with $1 \times$ protease inhibitor cocktail.

5. Scrape the cells using a cell lifter and pool lysates from the same condition into a $1.5-\mathrm{mL}$ microfuge tube.

6. Centrifuge the lysates for 2 minutes at $17,000 \times \mathrm{g}$ at $4^{\circ} \mathrm{C}$ to pellet cell debris.

7. To assess total Rho GTPase content in control and C21-treated cells, combine 20 $\mu \mathrm{L}$ of each cell lysate with $5 \mu \mathrm{L}$ of $4 \times$ Laemmli buffer in a clean microfuge tube. Heat for 5 minutes at $95^{\circ} \mathrm{C}$ and store at $-20^{\circ} \mathrm{C}$.

8. To assess activated Rho GTPase add $4 \mu \mathrm{g}$ of PAK-GST glutathione sepharose beads per tube of remaining lysates (see Note 6). 
9. Gently rotate the tubes on a wheel in the cold room for 45 minutes to 1 hour to allow the binding of the active GTPase to its effector PAK.

10. Briefly spin down the beads and eliminate supernatant.

11. Wash the beads 3 times with $1 \mathrm{~mL}$ of FISH buffer, centrifuge 1 minute at $\underline{10,000}$ $\mathrm{xg}$ between each wash.

12. Pellet the beads and resuspend in $20 \mu \mathrm{L}$ of $2 \times$ Laemmli buffer, heat for 5 minutes at $95^{\circ} \mathrm{C}$ to release the bead-bound proteins and store at $-20^{\circ} \mathrm{C}$.

13. The samples (total and activated) are now ready to be run on a $12 \%$ SDS-PAGE gel and analyzed by western blot with an anti-Rac 1 antibody using ImageJ software (see Fig. 3).

14. To establish the level of Racl activation in each sample, calculate the ratio between the amount of active Rac1 (bound to the PAK-GST glutathione sepharose beads) and the amount of Rac1 in the total cell lysate.

\subsection{Rho-GTPase overexpression protocol}

\subsubsection{Retroviral supernatant production}

1. Plate $2 \times 10^{6}$ HEK 293 T cells in 100 -mm tissue culture plates in $10 \mathrm{~mL}$ of DMEM growth medium. On the next day, the HEK $293 \mathrm{~T}$ cells should be $60-70 \%$ confluent.

2. For retrovirus component transfection, prepare 2 mixes in $1.5 \mathrm{~mL}$ microcentrifuge tubes: (a) $500 \mu \mathrm{L}$ of $150 \mathrm{mM} \mathrm{NaCl}$ and $14 \mu \mathrm{L}$ of Jet PEI and (b) $500 \mu \mathrm{L}$ of $150 \mathrm{mM} \mathrm{NaCl}$ and $7 \mu \mathrm{g}$ of DNA mix: $3.5 \mu \mathrm{g}$ pMXs-Puro based expression plasmid (in our case pMXs-Puro-GFP and pMXs-Puro-GFP-RacL61) + $1.22 \mu \mathrm{g}$ pC57GP + $1 \mu \mathrm{g}$ pCSI-G $+1.22 \mu \mathrm{g}$ salmon sperm DNA (see Note 7).

3. Mix (a) into (b) and incubate for 20 minutes at room temperature. Gently add the resulting mix dropwise with a $1000-\mu \mathrm{L}$ micropipette into the medium of the HEK 
$293 \mathrm{~T}$ cells and shake gently. Incubate for 4 to 5 hours and then replace with $10 \mathrm{~mL}$ of fresh DMEM growth medium.

4. After 3 days, carefully collect the culture medium with a $10-\mathrm{mL}$ sterile plastic pipette (see Note 8) and pass through a $0.45-\mu \mathrm{m}$ filter adapted to a 20 -mL syringe (see Note 9). Keep the retroviral supernatant on ice until infection (see Note 10).

\subsubsection{Infection of $B M M s$}

1. Plate $5 \times 10^{6}$ freshly isolated osteoclast precursors (Subheading 3.1, step 19) in a $100-\mathrm{mm}$ Petri dish with $10 \mathrm{~mL}$ of $\alpha$-MEM growth medium supplemented with 100 ng/mL M-CSF (see Note 11).

2. Change for fresh medium after 2 days and leave for 3 more days.

3. Aspirate the culture medium and immediately infect the osteoclast precursors with $5 \mathrm{~mL}$ retroviral supernatant (see subheading 3.5.1, step 3) combined with $5 \mathrm{~mL} \alpha$ MEM growth medium, $4 \mu \mathrm{g} / \mathrm{mL}$ hexadimethrine bromide and $100 \mathrm{ng} / \mathrm{mL}$ M-CSF (see Note 12). Incubate for $24 \mathrm{~h}$.

4. Remove medium and add $10 \mathrm{~mL} \alpha$-MEM growth medium with $100 \mathrm{ng} / \mathrm{mL}$ M-CSF and $3 \mu \mathrm{g} / \mathrm{mL}$ of puromycin to select infected cells. Use non-infected BMMs as control plate for selection efficiency.

5. After 2 days, replace medium by $10 \mathrm{~mL}$ of $\alpha$-MEM growth medium with 100 $\mathrm{ng} / \mathrm{mL} \mathrm{M}-\mathrm{CSF}$.

6. Culture the infected BMMs from 1 to 4 days ${ }_{2}$ depending on their confluence (see Note 13) before using them for osteoclast differentiation to observe the localization of the protein of interest for instance (see Fig. 4) and further experiments such as Rho_GTPase pull down assays or resorption assays. 


\section{Notes}

1. Optimize supernatant collection by tilting the plates; do not flush medium onto the cells attached at the bottom to collect more osteoclast precursors.

2. It is important to use Petri dishes and not tissue culture dishes otherwise osteoclast precursors adhere too firmly and it will be difficult to lift the cells without damaging, which is needed for splitting or replating at the appropriate density to perform the different assays described below.

3. Cells should never reach confluence, if necessary trypsinize and split 1:2 in new 100-mm Petri dishes.

4. During those 2 days, one can perform treatments with a pharmacological compound, for instance by adding $20 \mu \mathrm{M} \mathrm{C} 21$, an inhibitor of Dock5, which will hinder bone resorption.

5. Medium can be reduced to $2 \mathrm{~mL}$ for short-term treatments to save precious chemicals. To avoid acute DMSO toxicity, remove $2 \mathrm{~mL}$ of growth medium and add $100 \mu \mathrm{M} \mathrm{C} 21$. Remove the rest of medium and replace by the $2 \mathrm{~mL}$ of medium containing C21. Do the same for the DMSO-treated control. If using another solvent, test the toxicity on osteoclasts before doing the experiment.

6. Rac2 and Cdc42 activation can also be assessed with PAK-GST gluthatione sepharose beads whereas Rhotekin-RBD gluthatione sepharose beads have to be used for RhoA. These GTPases can be detected by western blot with the corresponding antibodies in subheading 3.4, step 13 .

7. This protocol is appropriate to produce retroviruses that can infect osteoclast precursors from either mouse or human origin. If only working with mouse material, pMXs-derived expression plasmids alone can be transfected in PlatinumE (Plat-E) Retroviral Packaging Cell Line (Cell Biolabs). This produces ecotropic 
retroviruses, which can only infect mouse or rat cells, that can be used to perform BMM infection as described in subheading 3.5.2.

8. The amount of virus produced depends on HEK 293T cell transfection efficiency. If using proteins with a fluorescent tag, it can be useful to check live by fluorescence microscopy.

9. The filtration allows the removal of the HEK $293 \mathrm{~T}$ cells that can easily detach from the tissue culture plate upon supernatant collection.

10. Fresh retrovirus supernatants are more efficient for BMM infection, but they can also be frozen in aliquots, kept at $-20^{\circ} \mathrm{C}$ for 24 hours and then at $-80^{\circ} \mathrm{C}$ until further use.

11. When using fresh retroviral supernatants, the BMMs production procedure must be synchronized with viral supernatant collection (Subheading 3.5.1).

12. At this step, osteoclasts precursors must be around_70\% confluent. If the confluence is higher, remove some cells with a short Accutase treatment.

13. The infection efficiency varies with the size and nature of the protein to be expressed. 


\section{Acknowledgements}

This work was supported by funding from CNRS and Montpellier University and by grants the Fondation pour la Recherche Médicale to A.B. (reference Equipe FRM DEQ20160334933) and the Fondation ARC pour la recherche sur le cancer to V. V.

(reference Projet Fondation ARC PJA 20151203109). Imaging was performed at the MRI Montpellier Ressources Imagerie imaging facility of Montpellier, France (www.mri.cnrs.fr). 


\section{References}

1. Weitzmann MN, Pacifici R (2006) Estrogen deficiency and bone loss: an inflammatory tale. J Clin Invest 116:1186-94.

2. Terpos E, Confavreux CB, Clézardin P (2015) Bone antiresorptive agents in the treatment of bone metastases associated with solid tumours or multiple myeloma. BoneKEy Rep. doi: 10.1038/bonekey.2015.113

3. Harre U, Schett G (2017) Cellular and molecular pathways of structural damage in rheumatoid arthritis. Semin Immunopathol 39:355-363. doi: 10.1007/s00281-017-0634-0 4. Boyle WJ, Simonet WS, Lacey DL (2003) Osteoclast differentiation and activation. Nature 423:337-42.

5. Georgess D, Machuca-Gayet I, Blangy A, Jurdic P (2014) Podosome organization drives osteoclast-mediated bone resorption. Cell Adhes Migr 8:191-204.

6. Touaitahuata H, Blangy A, Vives V (2014) Modulation of osteoclast differentiation and bone resorption by Rho GTPases. Small GTPases 5:e28119. doi: 10.4161/sgtp.28119

7. Takito J, Otsuka H, Inoue S, et al (2017) Symmetrical retrograde actin flow in the actin fusion structure is involved in osteoclast fusion. Biol Open 6:1104-1114. doi:

$10.1242 /$ bio. 025460

8. Brazier H, Stephens S, Ory S, et al (2006) Expression profile of RhoGTPases and RhoGEFs during RANKL-stimulated osteoclastogenesis: identification of essential genes in osteoclasts. J Bone Miner Res Off J Am Soc Bone Miner Res 21:1387-1398. doi: 10.1359/jbmr.060613

9. Ory S, Brazier H, Pawlak G, Blangy A (2008) Rho GTPases in osteoclasts: orchestrators of podosome arrangement. Eur J Cell Biol 87:469-477. doi: 10.1016/j.ejcb.2008.03.002

10. Chellaiah MA, Soga N, Swanson S, et al (2000) Rho-A is critical for osteoclast podosome organization, motility, and bone resorption. J Biol Chem 275:11993-2002.

11. Ory S, Munari-Silem Y, Fort P, Jurdic P (2000) Rho and Rac exert antagonistic functions on spreading of macrophage-derived multinucleated cells and are not required for actin fiber formation. J Cell Sci 113 ( Pt 7):1177-88.

12. Croke M, Ross FP, Korhonen M, et al (2011) Rac deletion in osteoclasts causes severe osteopetrosis. J Cell Sci 124:3811-21. doi: 10.1242/jcs.086280

13. Leung R, Cuddy K, Wang Y, et al (2011) Sbds is required for Rac2-mediated monocyte migration and signaling downstream of RANK during osteoclastogenesis. Blood 117:2044-2053. doi: 10.1182/blood-2010-05-282574

14. Wang Y, Lebowitz D, Sun C, et al (2008) Identifying the relative contributions of rac1 and rac2 to osteoclastogenesis. J Bone Min Res 23:260-70.

15. Zhu M, Sun B, Saar K, et al (2016) Deletion of Rac in Mature Osteoclasts Causes Osteopetrosis, an Age-Dependent Change in Osteoclast Number, and a Reduced Number of Osteoblasts In Vivo: RAC1/RAC2 DOUBLE KNOCK-OUT IN OSTEOCLASTS. J Bone Miner Res 31:864-873. doi: 10.1002/jbmr.2733

16. Brazier H, Pawlak G, Vives V, Blangy A (2009) The Rho GTPase Wrch1 regulates osteoclast precursor adhesion and migration. Int J Biochem Cell Biol 41:1391-1401. doi: 10.1016/j.biocel.2008.12.007

17. Ory S, Brazier H, Blangy A (2007) Identification of a bipartite focal adhesion localization signal in RhoU/Wrch-1, a Rho family GTPase that regulates cell adhesion and migration. Biol Cell 99:701-16. doi: 10.1042/BC20070058

18. Georgess D, Mazzorana M, Terrado J, et al (2014) Comparative transcriptomics reveals RhoE as a novel regulator of actin dynamics in bone-resorbing osteoclasts. Mol Biol Cell 25:380-96. doi: 10.1091/mbc.E13-07-0363 
19. Ito Y, Teitelbaum SL, Zou W, et al (2010) Cdc42 regulates bone modeling and remodeling in mice by modulating RANKL/M-CSF signaling and osteoclast polarization. $\mathrm{J}$ Clin Invest 120:1981-93. doi: 10.1172/JCI39650

20. Fort P, Blangy A (2017) The Evolutionary Landscape of Dbl-Like RhoGEF Families: Adapting Eukaryotic Cells to Environmental Signals. Genome Biol Evol 9:1471-1486. doi: $10.1093 / \mathrm{gbe} / \mathrm{evx} 100$

21. Gadea G, Blangy A (2014) Dock-family exchange factors in cell migration and disease. Eur J Cell Biol 93:466-477. doi: 10.1016/j.ejcb.2014.06.003

22. Tcherkezian J, Lamarche-Vane N (2007) Current knowledge of the large RhoGAP family of proteins. Biol Cell Auspices Eur Cell Biol Organ 99:67-86. doi: 10.1042/BC20060086

23. Vives V, Laurin M, Cres G, et al (2011) The Rac1 exchange factor Dock5 is essential for bone resorption by osteoclasts. J Bone Miner Res Off J Am Soc Bone Miner Res 26:1099-1110. doi: 10.1002/jbmr.282

24. Faccio R, Teitelbaum SL, Fujikawa K, et al (2005) Vav3 regulates osteoclast function and bone mass. Nat Med 11:284-290. doi: 10.1038/nm1194

25. Takegahara N, Kang S, Nojima S, et al (2010) Integral roles of a guanine nucleotide exchange factor, FARP2, in osteoclast podosome rearrangements. FASEB J Off Publ Fed Am Soc Exp Biol 24:4782-4792. doi: 10.1096/fj.10-158212

26. Steenblock C, Heckel T, Czupalla C, et al (2014) The Cdc42 Guanine Nucleotide Exchange Factor FGD6 Coordinates Cell Polarity and Endosomal Membrane Recycling in Osteoclasts. J Biol Chem 289:18347-18359. doi: 10.1074/jbc.M113.504894

27. Mullin BH, Mamotte C, Prince RL, Wilson SG (2014) Influence of ARHGEF3 and RHOA Knockdown on ACTA2 and Other Genes in Osteoblasts and Osteoclasts. PLoS ONE 9:e98116. doi: 10.1371/journal.pone.0098116

28. McMichael BK, Scherer KF, Franklin NC, Lee BS (2014) The RhoGAP activity of myosin IXB is critical for osteoclast podosome patterning, motility, and resorptive capacity. PLoS ONE 9:e87402. doi: 10.1371/journal.pone.0087402

29. Vives V, Cres G, Richard C, et al (2015) Pharmacological inhibition of Dock5 prevents osteolysis by affecting osteoclast podosome organization while preserving bone formation. Nat Commun 6:6218. doi: 10.1038/ncomms7218

30. Lassaux A, Sitbon M, Battini JL (2005) Residues in the murine leukemia virus capsid that differentially govern resistance to mouse Fv1 and human Ref1 restrictions. J Virol 79:6560-4.

31. Battini JL, Rasko JE, Miller AD (1999) A human cell-surface receptor for xenotropic and polytropic murine leukemia viruses: possible role in $\mathrm{G}$ protein-coupled signal transduction. Proc Natl Acad Sci U A 96:1385-90. 


\section{Figure Legends.}

Figure 1: RANKL-induced in vitro osteoclast differentiation of BMMs. Phase contrast images, taken during the osteoclast differentiation procedure described in subheading 3.2 , of (A) bipolar elongated BMMs (arrows), (B) undergoing fusion (arrows) after 2 days in the presence of RANKL and (C) forming differentiated osteoclasts after 4 days. Scale bar $=100$ $\mu \mathrm{m}$.

Figure 2: Resorption activity of osteoclasts expressing or not the Rac1 GEF Dock5. (A) Resorption areas (in white) were visualized after von Kossa staining of Osteo Assay stripwell plated with Dock5 wild-type $\left(\right.$ Dock $\left.5^{+/+}\right)$or knockout $\left(\right.$Dock $\left.5^{-/}\right)$osteoclasts [23] according to the method described in subheading 3.3. (B) Quantification of resorption area per osteoclast (OC) for each genotype, determined from the average and SEM of 4 wells per genotype as described in subheading 3.3, step 8 .

Figure 3: Effect of the Dock5 inhibitor C21 on the activity of Rac1 in osteoclasts. Osteoclasts were treated for one hour with $0.5 \%$ DMSO containing (+) or not (-) $100 \mu \mathrm{M}$ C21. (A) Total Rac1 and active GTP-bound Rac1 were analyzed by western blot according to the procedure described in Subheading 3.4. (B) For each condition the amount of Rac1 was determined using ImageJ and the percentage of active Rac1 normalized to total Rac1.

Figure 4: Expression of GFP and GFP-Rac1-Q61L in Dock5 ${ }^{-/-}$osteoclasts. BMMs were prepared from Dock $5^{-/-}$mice according to the method described in Subheading 3.2. Viral supernatants were produced from pMXs-Puro vectors expressing GFP or GFP-fused active Q61L mutant of Rac1_and used to infect Dock5-/- BMMs, according to the procedures described in Subheading 3.5. BMMs were differentiated into osteoclasts following the protocol in Subheading 3.4. Fixed osteoclasts were imaged for GFP (left panels) and Hoechst- 
labeled nuclei (middle panels), with the two channels merged in the right panels to show the multinucleated GFP-positive osteoclasts. Scale bar: $50 \mu \mathrm{m}$. 
$\mathbf{B} f^{a}-a \quad \mathbf{C}$ - o) $\rightarrow$ ? . $=0$ $\therefore \quad: 03-$

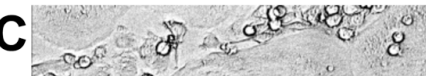
$08 \% 0$

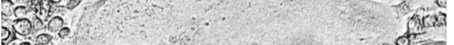
62 10 $+4$

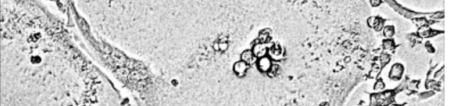

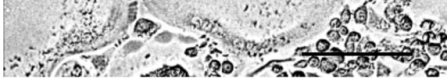



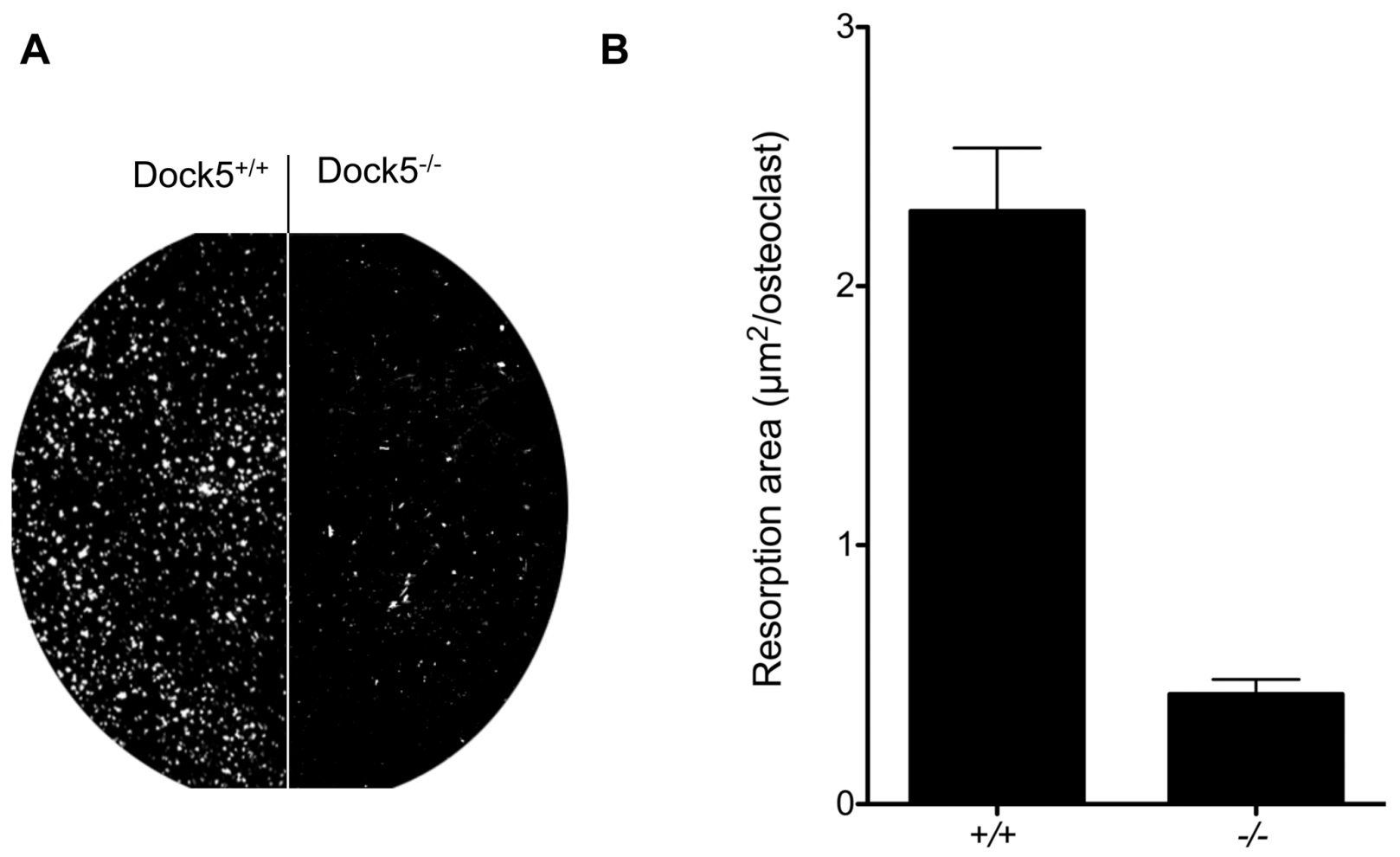
A

B

Active Rac1 (\%)

$\mathrm{C} 21(100 \mu \mathrm{M})$
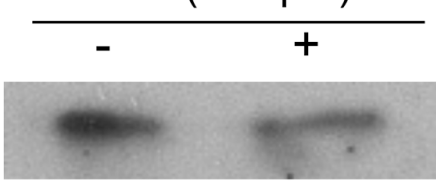

active

Rac1

total

Rac1

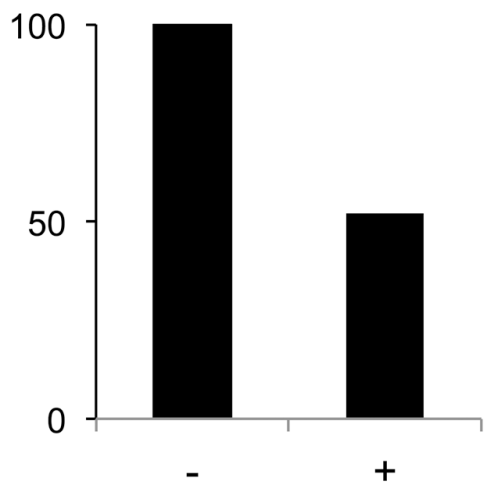




\section{GFP}

Hoechst

\section{Merge}

Protein expressed:

GFP
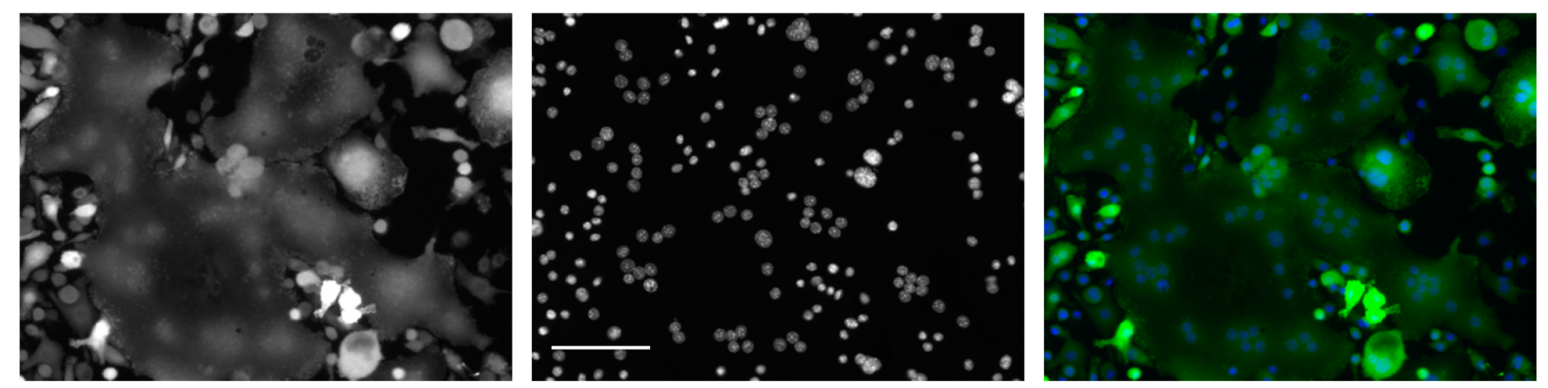

GFPRac1Q61L
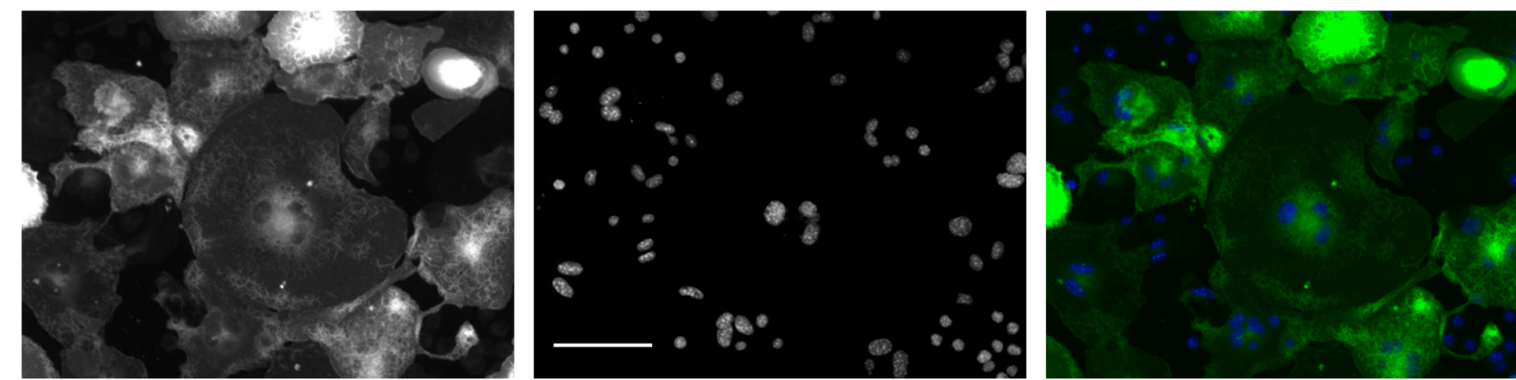